http://dx.doi.org/10.5935/1981-2965.20130016 Artigo Cientifico

http://www.higieneanimal.ufc.br

\title{
Dragon's blood (Croton lechleri Mull., Arg.): an update on the chemical composition and medical applications of this natural plant extract. A review
}

Sangue de Dragão (Croton lechleri Mull., Arg.): composição química e atualização dos principais estudos sobre sua aplicação. Uma revisão

\section{Thiago Vaz Lopes¹, Samuel Rodrigues Félix*1, Sandro de Vargas Schons²; Márcia de Oliveira Nobre ${ }^{1}$}

\footnotetext{
${ }^{1}$ Programa de Pós Graduação em Veterinária - Universidade Federal de Pelotas

(UFPel), Caixa postal 354 - Campus Universitário, CEP: 96010-900 - Pelotas/RS

*vlopes.thiago@gmail.com

2 Departamento de Medicina Veterinária - Campus de Rolim - Universidade Federal de Rondônia (UNIR) Av. Norte Sul, 7300 - Nova Morada, CEP: 78987-000 Rolim de

$$
\text { Moura - RO }
$$
}

\begin{abstract}
Plants of the amazon region are commonly applied for medicinal uses, foremost among these is the latex producing Croton lechleri. The taspine rich latex has anti-inflammatory, wound healing, and soothing properties, among several others. This review summarizes the most important research findings regarding the applications of this plant extract. Public receptiveness to plant based treatments result in indiscriminate use of these compounds, often with no scientific validation. Likewise, Croton lechleri extracts must be subjected to safety testing and clinical trials before its products are made available, in a commercial scale, with recognized therapeutic functions.
\end{abstract}

Key words: Herbal, Croton lecheri, taspine, update.

Resumo: Na região amazônica muitas plantas são usadas popularmente para fins medicinais, uma espécie de destaque é o Croton lechleri, produtora de um látex cuja composição química é rica no alcalóide taspina. Este possui ação anti-inflamatória, analgésica e cicatrizante reconhecida. Objetivou-se assim revisar as publicações mais 
recentes com o intuito de reunir e atualizar os principais estudos referentes a aplicações desta planta. A receptividade popular por receitas tradicionais usando plantas medicinais faz com que, muitas vezes estas sejam usadas sem os devidos estudos científicos para validação de suas aplicações terapêuticas. Da mesma forma, as aplicações do Croton lechleri devem sofrer os devidos ensaios clínicos a fim de colocar os produtos e subprodutos a base desta planta no mercado, em escala comercial, com suas funções terapêuticas reconhecidas.

Palavras-chave: fitoterápico; Croton lecheri; taspina; atualização.

Autor para correspondência. E.Mail: *vlopes.thiago@gmail.com Recebido em 20.3.2012. Aceito em 10.5.2013

\section{Introdução}

A utilização de plantas para fins terapêuticos destaca-se dentro do repertório cultural (OLIVEIRA et al., 2010). A medicina popular vem acumulando durante séculos o conhecimento empírico, através de observações sobre o uso e a eficácia das plantas medicinais, simbolizando, em alguns casos, o único recurso terapêutico de várias comunidades e grupos étnicos com pouco ou nenhum acesso a serviços formais de saúde
(VALLE et al., 2013). A prática do consumo e frequentes prescrições partem deste conhecimento observacional.

Sendo assim, as informações terapêuticas que foram sendo acumuladas ao longo do tempo são importantes indicativos da ação farmacológica destas plantas (MACIEL et al., 2002), entretanto, essa ação deve ser comprovada por estudos acadêmicos. 
Lopes et al., Revista Brasileira de Higiene e Sanidade Animal (v.7, n.2) p. 167 - 191 (2013)

Uma alternativa para os Com descrita atividade antitratamentos na medicina convencional é inflamatória, antibiótica, antioxidante e a utilização de varias partes das plantas cicatrizante, $\quad$ seus estudos medicinais tais como a raiz, caule, seiva, folha, flores, frutos ou sementes, dependendo da espécie vegetal (DINIZ et al., 2013). Muitas destas plantas não têm seus efeitos descritos em estudos científicos, contudo, este cenário vem mudando e tem se tomado um número crescente de iniciativas a fim de garantir o acesso seguro e o uso racional dessas plantas e fitoterápicos (BRASIL, 2009). Em função disso, cada vez mais se procura compostos naturais bioativos de plantas da Amazônia, visando estabelecer ensaios biológicos como modelos para novas investigações nesse campo, a fim de preservar, estudar e explorar racionalmente o bioma amazônico (DI STASI, 2002). Neste contexto destaca-se a espécie Croton lechleri, conhecida popularmente como sangue de dragão, sangue de grado ou sangue de drago (PERCY et al., 2007). farmacológicos e clínicos realizados até 2002 foram reunidos por JONES (2003).

Desta forma, este estudo teve como objetivo reunir dados da literatura referentes à biologia e composição química do Croton lechleri e do seu extrato. Mais que isso, esse estudo atualiza o que se sabe sobre as aplicações do sangue de dragão, reunindo os principais ensaios referentes ao tema publicados na ultima década.

\section{Croton lechleri:}

Com cerca de 1.200 espécies e 1400 binômios o Croton é um dos maiores gêneros das Euphorbiaceae (GOVAERTS et al., 2000). Da subclasse $\quad$ Rosidae, classe Magnoliopsida, o gênero tem distribuição nas Antilhas, Americas, África continental e Madagascar 
(WEBSTER, 2001). O C. lechleri, com sinônimos botânicos C. draco var cordatus Mull. Arg e Oxydectes lecheri Kuntze (ZEVALLOS-POLLITO \& TOMAZELLO, 2004), é popularmente conhecido pelos nomes: sangue de drago, sangue de dragão e sangue de grado. O gênero no Brasil ocorre principalmente nos estados do Acre, Bahia, Ceará, Goiás, Maranhão, Mato Grosso do Sul, Minas Gerais, Paraná, Paraíba, Pernambuco, Rio de Janeiro, Rondônia e São Paulo (AZEVEDO et al., 2008).

LINNAEUS em 1753 propôs o gênero e Müller em 1873 retratou com diversos táxons novos que foram e vêm sendo propostos, sendo que as espécies brasileiras ainda não foram totalmente revisadas (SECCO, 2009). Esse fato torna confusa a taxonomia do Croton na região e estudos recentes na América do Sul ainda não foram eficientes para que se possa precisar os limites específicos da ocorrência do C. lechleri. Da mesma forma, na região amazônica há uma grande quantidade de espécimes necessitando de uma melhor identificação em herbários, indicando a necessidade de se gerar mais conhecimento taxonômico sobre o gênero (GUIMARÃES \& SECO, 2010). Além disso, a identificação do $C$. lechleri é complexa, com grande variação morfológica (forma, disposição, consistência, coloração e tamanho das folhas, tricomas e glândulas), idade, distribuição geográfica e processos adaptativos (ZEVALLOS-POLLITO \& TOMAZELLO, 2007).

O C. lechleri apresenta um comportamento fenológico cíclico, com aproximadamente cinco meses de duração. A floração e frutificação ocorrem de julho a agosto e a maturação e disseminação entre setembro e outubro. A floração coincide com o período seco e a disseminação com o inicio do período de chuvas 
(AZEVEDO et al., 2008). Suas sementes são muito pequenas e se disseminam geralmente pelo vento, por aves, pela água e por formigas (KING et al., 1997; LEAL, 2003).

A planta é encontrada em florestas com planície de inundação, com solos férteis e úmidos, à margem de rios e riachos com boa drenagem, assim como em locais alterados como fragmentos de florestas e especialmente em campos de cultivos abandonados tornando-se importante na recuperação de áreas degradadas nos diversos países em que ocorre naturalmente. Não suporta períodos longos de inundação e solos perturbados e cultivados, como uma clássica espécie pioneira (FORERO et al., 2000; AZEVEDO et al., 2008). Tolerante a sombra inicial parcial, mas que se desenvolve melhor a plena luz, domina ou se estabelece no estrato intermediário do bosque (codominante), mostrando preferência por solos variando de extremamente ácidos a neutros de textura média a fina (de arenoso a argiloso), tolerando também solos degradados. Sua densidade populacional varia de três a 15 indivíduos por hectare, mas esporadicamente pode também ser encontrado em populações de 90 a 150 árvores por hectare. No Brasil, apresentam-se de forma espontânea em vários estados, sendo abundante no Acre e em Rondônia principalmente as margens do rio Madeira (FORERO et al., 2000; BRITO et al., 2007).

Entre os temas mais estudados na química de produtos naturais, farmacologia e etnofarmacologia, estão às espécies desse gênero e suas substâncias químicas. É esperado que se acumule rapidamente novos dados sobre suas substâncias e respectivos efeitos farmacológicos. Um dos mais importantes centros de diversidade desse gênero se encontra no Brasil, pois existem, ao menos, 354 espécies de Croton nativas conhecidas (SECCO et 
al, 2001; SALATINO et al., 2007) descritos como demonstrado na Tabela

muitas delas com efeitos terapêuticos já $\quad 1$.

Tabela 1. Espécies de Croton e suas respectivas distribuições geográficas como também suas descritas indicações terapêuticas citados em publicações recentes.

Table 1. Croton species and their geographic distribution as well as their therapeutic indications described in recent publications cited.

\begin{tabular}{|c|c|c|c|}
\hline Espécie & Distribuição & Indicação Terapêutica & Referencia \\
\hline C. argyrophylloides & América & Diabetes e as doenças venéreas & $\begin{array}{l}\text { FRANÇA- } \\
\text { NETO et al., } \\
2012\end{array}$ \\
\hline C. bonplandianum & Asia/América & Repelente contra os insetos & $\begin{array}{l}\text { AHMAD_et } \\
a l ., 2008\end{array}$ \\
\hline C. cajucara & Brasil & $\begin{array}{l}\text { Analgésico, anti-inflamatório, } \\
\text { antiulcerogênico, hipoglicêmico, } \\
\text { hipolipidêmico }\end{array}$ & $\begin{array}{l}\text { SILVA et al., } \\
2005\end{array}$ \\
\hline C. caudatus & América/Ásia & $\begin{array}{c}\text { Tratamento da malária, febre ardente, } \\
\text { convulsões, artrite reumática e } \\
\text { dormência. }\end{array}$ & $\begin{array}{c}\text { GUO, et al., } \\
2010\end{array}$ \\
\hline C. celtidifolius & Brasil & Tratamento de doenças inflamatórias & $\begin{array}{l}\text { NEIVA } \text { et al., } \\
2008\end{array}$ \\
\hline C. lechleri & América & $\begin{array}{l}\text { Tosse, gripe, diarreia, úlceras gástricas, } \\
\text { cicatrizante, tratar herpes, germicida } \\
\text { após extração dental e feridas bucais }\end{array}$ & $\begin{array}{c}\text { MURILLO et } \\
\text { al., } 2001\end{array}$ \\
\hline C. lechleri & América & $\begin{array}{l}\text { Anti-inflamatória, antibiótica, } \\
\text { antioxidante e cicatrizante }\end{array}$ & $\begin{array}{l}\text { FÃO } \text { et al., } \\
\quad 2012\end{array}$ \\
\hline C. lechleri & América & $\begin{array}{l}\text { Anti-inflamatória, analgésico bucal, } \\
\text { cicatrização de ulcera gástrica, } \\
\text { antidiarreico, }\end{array}$ & $\begin{array}{l}\text { ZEVALLOS- } \\
\text { POLLITO et } \\
\text { al., } 2007\end{array}$ \\
\hline C. palanostigma & Brasil & $\begin{array}{l}\text { Cura de feridas, antimicrobiano, } \\
\text { controlador da diarreia, cicatrização de } \\
\text { úlcera gástrica, tratar inflamação } \\
\text { intestinal e anti-emético. }\end{array}$ & $\begin{array}{c}\text { MILLER et } \\
\text { al., } 2000\end{array}$ \\
\hline C. zehntneri & América & $\begin{array}{l}\text { Sedativo, estimulante de apetite, } \\
\text { estomáquico, antiespasmódico, anti- } \\
\text { anorexígeno, analgésico, ansiolítico, } \\
\text { tratamento de distúrbios gastrintestinais, } \\
\text { irritabilidade e ansiedade }\end{array}$ & $\begin{array}{c}\text { OLIVEIRA et } \\
a l ., \text { 2001). }\end{array}$ \\
\hline
\end{tabular}

\section{Características Químicas}

\section{Latex de Croton lechleri}

A importância do gênero Croton

aumenta consideravelmente do ponto de

vista médico por possuir grande

quantidade de alcalóides bioativos

(AMARAL \& BARNES, 1997). Dessa

forma, o interesse pelo estudo dessas plantas é justificado, porém ainda são

poucos os trabalhos avaliando os

produtos do $\quad$ lechleri

(MILANOWSKI et al., 2002).

O alcalóide metabolizado pelo

material foliar do $C$. lechleri foi similar

ao do látex produzido pelo mesmo.

Sendo a taspina o único alcalóide 
detectado no látex de indivíduos adultos

(CAI et al., 1993a; CAI et al., 1993b), enquanto que em outras partes da planta (folhas, flores, inflorescências, casca do tronco, raízes e sementes) outros alcalóides como magnoflorina, isoboldina, taliporfina, também foram encontrados (MILANOWSKI et al., 2002). O exsudado das glândulas da base das folhas é a única amostra que não apresenta acúmulo de alcaloides, o que se justifica, pois estas tem a função de secretarem uma substância açucarada que serve para atrair formigas que atuam como dispersoras de sementes e polinizadoras, necessitando a ausência de alcalóides por serem potencialmente tóxicos aos insetos. Essa característica sugere que estes alcalóides apresentam atividade repelente, potencial este que deve ser averiguado em estudos controlados.

Os frutos e as folhas exalam um odor agradável ao final da tarde, mostrando uma possível utilização como planta aromática, um potencial que também é pouco explorado (CAI et al., 1993a; CAI et al., 1993b). As Euphorbiaceae, em sua maioria, não são conhecidas como aromáticas, porém, algumas espécies de Croton contêm óleos voláteis, bem como fenilpropanóides e terpenóides (mono e sesquiterpenos) na sua composição (OLIVEIRA et al., 2001; LOPES et al., 2003; SALATINO et al., 2007).

Em estudos químicos realizados com o látex do Croton lechleri, demonstrou-se que os constituintes majoritários são compostos polifenólicos, representando cerca de 90\% do peso seco (CAI et al., 1993a). Foram isolados a catequina, epicatequina, epicatequina, galocatequina, proantocianidinas, B-1 e B-4, gallocatequina, os diterpenos Korberina A e B, os compostos minoritários 1,3,5 trimetoxi-benzeno e o 2,4,6 trimetóxi-fenol (CAI et al.,1991; PALAZZINO et al., 1997; MACIEL et 
al., 2002; SILVA et al., 2002), 3',4-Odimetilcedrusina, que tem ação sobre os radicais livres e também foram encontrados os alcaloides como piridina, aportineindole, quinoleína, tropanos, ácidos graxos insaturados, anthraquinones e triterpenos. (MARINO et al., 2008).

\section{Taspina}

A taspina é um alcalóide com uma estrutura dilactone e um átomo de nitrogênio não incluído em um anel heterocíclico, sendo encontrado no látex de três espécies de Croton: $C$. draco, $C$. lechleri e $C$. palanostigma. Esse composto tem sido obtido também de plantas fontes de benzilisoquinolinas e biogeneticamente relacionadas à alcalóides, como Berberidaceae e Magnoliaceae (SALATINO et al., 2007). A taspina foi isolada da casca e do látex desta espécie, que demostrou ser o principal princípio ativo responsável pela cicatrização de feridas (CAI et al., 1993a; CAI et al., 1993b;
CUNHA, 2007). O crescente interesse em estudos da seiva do Croton lechleri é principalmente devido à presença deste alcaloide (MONTOPOLI et al., 2012), o qual atua também como importante estimulador da migração dos fibroblastos nas feridas (PIETERS, 1993). Tamanha a sua importância que diversos autores mencionam a necessidade de isolar a taspina e estudar o seu potencial individual (FAYAD et al., 2009; ROLLINGER et al., 2006; ZHANG et al., 2010). São também conhecidas as suas propriedades antiinflamatórias, antioxidantes e por ter atividade citotóxica à células cancerígenas (PIETERS, 1993; MAIA et al., 2006). Se demonstrou que pode restringir o desenvolvimento de micélio do fungo Leucoagaricus gongylophorus L. (FRANCO et al., 2013), já ITOKAWA et al. (1991) relatam uma potente atividade contra células $\mathrm{KB}$ e V-79. Assim, a taspina tem ganhado destaque quando se avalia os extratos de 
C. lechleri e estudos futuros devem considerar cada vez mais a importância deste composto.

\section{Aplicação Clinica:}

A espécie $C$. lechleri é utilizada como planta medicinal há séculos, ela atua como anti-inflamatório, cicatrizante de feridas, antidiarreico, analgésico bucal e para a cura de úlceras estomacais $\quad$ (JONES, 2003; ZEVALLOS-POLLITO et al., 2007). O amplo uso popular ressalta a necessidade de realização de pesquisas, não só para demonstrar os efeitos terapêuticos do sangue de dragão e da taspina, como também para ajuste das indicações e doses. Esse tipo de pesquisa ainda é escasso, o que é potencializado pelo conceito errôneo de que plantas são medicamentos naturais, portanto livres de efeitos adversos. Outro ponto que deve sofrer averiguação cientifica é o seu potencial toxico e mutagênico, uma vez que muitas plantas vêm sendo usadas como fitoterápicos sem nenhum conhecimento dos seus efeitos em grandes doses e/ou longo prazo (VIEIRA et al., 2009).

\section{Teste de toxicidade aguda}

Para ensaios de toxicidade, ROSSI et al. (2013) utilizaram ratos C57BL. A toxicidade aguda foi estimada administrando doses crescentes do latex, por via oral e intraperitoneal. Os animais foram observados diariamente durante 14 dias para mortalidade, mudanças comportamentais e outros sinais de toxicidade. O extrato do Croton mostrou uma dose letal para $50 \%$ da população (DL50) de $356 \mathrm{mg} / \mathrm{kg}$ por via intraperitoneal e $500 \mathrm{mg} / \mathrm{kg}$ por via oral, e indicou efeitos tóxicos moderados in vivo.

As investigações toxicológicas averiguadas foram para eventual toxicidade de curto prazo, mas estudos de toxicidade a longo prazo devem também ser conduzidos, visto que efeitos adversos podem ocorrer depois 
de um período prolongado, de meses ou até mesmo anos (AYALA et al., 2010).

Em um estudo realizado por

FÃO et al. (2012) analisou-se o potencial mutagênico da seiva de Croton lechleri em raízes de cebola. Estes concluíram que não houve alteração, sendo indicativo da não ocorrência de mutagenicidade. $\mathrm{Na}$ mesma linha, ROSSI et al. (2003) observaram, em estudo realizado com teste Ames em estirpes de Salmonella typhimurium T98 e T100, que não houve atividade mutagênica. Estes mesmos autores demonstram que a mutagenicidade de 2-aminoantraceno foi completamente inibida em TA98, enquanto foi reduzida em mais de $90 \%$ na estirpe TA100, quando aplicado na presença do latex. Esses resultados demonstram ainda que a seiva exibe atividade antiproliferativa para células K562 (células humanas leucêmicas). Estes autores indicam, portanto, a segurança do uso de Sangue de Dragão como um remédio natural, sem riscos genotóxicos, além de sugerirem ação antitumoral e antimutagênica (ROSSI et al., 2003; JONES, 2003; SALATINO et al., 2007). Pode-se concluir, assim, que a seiva desta planta possui baixa toxidade celular, sendo a mesma tolerada para estudos clínicos.

\section{Antiúlcera e atividade antidiarreica}

Seu potencial como cicatrizante de ulceras gástricas e seu efeito antibacteriano foram comprovados em um estudo realizado por MILLER et al. (2000), no qual animais experimentais foram induzidos à ulceração gástrica e tratados com C. lechleri. A cura foi de uma magnitude semelhante ao grupo controle, que recebeu combinação de penicilina e estreptomicina. Observouse que o conteúdo bacteriano da úlcera foi bastante reduzido, como também o teor de granulócitos, sendo elas menos inflamadas e com carga bacteriana menor, o que potencializou a cura, salientando a sua superioridade ao uso 
Lopes et al., Revista Brasileira de Higiene e Sanidade Animal (v.7, n.2) p. 167 - 191 (2013)

dos antibióticos por ter a ação

antinflamatória como aditivo. Essa ação

é justificada pela variedade de produtos

químicos que atuam em conjunto no

látex. Além disso, a seiva do C. lechleri

estimula a secreção de pepsina,

favorecendo a degradação de proteínas

de fonte alimentar, consequentemente,

melhorando a digestão e facilitando

assim o processo de cicatrização

gástrica, explicando assim seu uso e sua

eficácia em casos de dispepsia gástrica.

A administração oral da seiva de sangue

de dragão também tem um efeito

antioxidante em mucosa gástrica

reduzindo a peroxidase, o que aumenta

a sua ação citoprotetora (SANDOVAL

et al., 2006).

O uso dessa seiva como

antidiarreico já foi bem estabelecido (JONES, 2003) e novos estudos vem edificando o conhecimento sobre esse tema. Se demonstrou que o seu uso leva

a uma diminuição ou bloqueio da capsaicina, podendo limitar a diarreia por reduzir a secreção de fluido intestinal. Isso se deu pela sua capacidade de inibir, de forma seletiva,

a circulação de eletrólitos epiteliais (SANVODAL et al., 2008).

\section{Anticancerígena}

A atividade de proteção do $C$. lechleri contra mutagênicidade através de sua atividade biológica sugere seu emprego como adjuvante no tratamento contra câncer e como preventivo em alimentos funcionais (ROSSI et al., 2003). Em outro estudo do mesmo grupo, feito para comprovar esta hipótese, se avaliou o efeito antiproliferativo do sangue de dragão, testado contra linhagem de carcinoma de células do cólon humano (LoVo) e carcinoma hepatocelular humano (HepG2) e demonstraram, mais uma vez, a eficácia anticâncer desta planta amazônica e seus derivados. Estes autores sugerem o C. lechleri como aditivo alimentar, visto que oferece uma proteção eficaz contra o potencial 
mutagênico das aminas heterocíclicas presentes nos alimentos. CASTRO et al. (2012) também demonstraram efeitos citotóxicos sobre as linhas de células cancerosas humanas e exerceu efeitos anti-tumorais em camundongos, eles demonstraram também toxidade aguda moderada do Croton lechleri sobre as células HeLa (câncer cervical) e SKOV3 (câncer de ovário). Nessa mesma linha, MONTOPOLI et al., (2013) demonstrou resultados promissores nas linhagens celulares SK23 (melanoma humano) e HT29 (tumor intestinal). BEZERRA et al., (2009) trabalhou com Croton regelianus, obtendo uma inibição do crescimento do tumor em $59 \%$, o que indica que as espécies Croton pode ser um importante fonte de compostos com efeitos anti-tumorais e citotóxicos em células HeLa. O óleo essencial extraído da casca do tronco do Croton lechleri, em um estudo realizado por ROSSI et al., (2011), apresentou-se como não citotóxico e é genotoxicamente seguro nas condições testadas com interessantes propriedades protetoras para a mutagenicidade.

\section{Ginecologia}

O uso do Croton para tratamentos ginecológicos já foi estabelecido (JONES, 2003), e seu efeito sobre tumores genitais (BEZERRA et al., 2009; CASTRO et al., 2012) pode ser o motivo real de sua eficácia no uso popular. Para averiguar a segurança de se usar o $C$. lechleri para esse fim, AYALA et al. (2010) avaliaram o efeito irritante deste em genitalia de coelhas.

Foi realizada administração tópica intra-vaginal de duas concentrações (1\% e 5\%), para a avaliação da toxicidade, sendo observadas as condições médicas em geral e a aparência física da vagina e períneo como também as marcas de fluxo, eritema e edema. Não houve aspectos clínicos significativos e o uso 
do extrato vegetal parece seguro nesses

casos.

\section{Demais efeitos terapêuticos}

A seiva do $C$. lechleri tem diversas outras funções terapêuticas descritas, incluindo ação imuno estimulante, antibacteriana, antiviral, além de ser indicada contra diarreias de diversas causas, inclusive aquelas associadas ao vírus da imunodeficiência humana. Estas funções, incluindo ensaios pré-clínicos e clínicos conduzidos com o sangue de dragão, foram revisadas por JONES (2003). Este mesmo autor relata o uso de produtos comerciais a base de sangue de dragão, disponíveis nos Estado Unidos.

O NSF (Normal Stool Formula ${ }^{\mathrm{TM}}$ ) é um suplemento alimentar cuja função é promover a produção de fezes normais (controlar diarreia crônica). O principal principio ativo neste produto, de acordo com os produtores, é a taspina e o produto também já sofreu ensaios clínicos indicativos de sua eficácia.

\section{Considerações Finais:}

Conforme descrito e concordando com o que vem sendo demonstrado para o sangue de dragão, a maioria dos estudos realizados com este composto confirma a função sugerida na medicina popular. Evidentemente que há um viés de publicação nestes casos, sendo que aqueles efeitos que são avaliados e negados raramente são publicados. De qualquer forma, não há duvidas que o látex obtido a partir da seiva de $C$. lechleri tem atividades biológicas diversas, muitas das quais podem e devem ser aplicadas na medicina humana e veterinária.

O mercado brasileiro parece ainda ser muito receptivo às receitas tradicionais de fitoterápicos, sendo pouco exigente quanto a sua validação cientifica. Sendo assim, ensaios clínicos, com compostos devidamente caracterizados e manipulados, não são tão comuns no país. Entretanto, em outros países, o sangue de dragão e a 
taspina já estão sendo usados em produtos comerciais ligados à indústria farmacêutica (vide JONES 2003). As recentes exigências da Agencia Nacional de Vigilância Sanitária (ANVISA) com relação à caracterização e validação de fitoterápicos pode mudar esse cenário. Por outro lado, quando a exigência de fiscalização e validação parte do mercado consumidor, a pressão sobre as empresas produtoras é muito maior e o Brasil ainda carece de consumidores educados nesse sentido, com relação a produtos da medicina tradicional.

Arvores do gênero Croton são de ampla distribuição na metade norte do Brasil e algumas plantações para exploração da seiva são conhecidas, ainda que pouco tecnificadas. Sendo assim, a validação dos efeitos terapêuticos dessa seiva também vem ao encontro ao interesse econômico de comunidades de pequenos produtores destas regiões, que se beneficiariam de um interesse industrial tanto do látex bruto quanto da taspina por parte da indústria farmacêutica.

Neste estudo, ficou claro que o numero de experimentos para comprovar e/ou validar funções e aplicações do sangue de dragão parece ter desacelerado desde a publicação do trabalho de JONES (2003) e pouco foi realizado com relação a ensaios clínicos em medicina humana ou veterinária. Os principais avanços parecem ter sido na questão da toxicidade e da segurança do uso deste extrato vegetal. Os ensaios de toxicidade que vem sendo desenvolvidos, ainda que estejam em fase preliminar, vão de encontro com aquilo que esta sendo exigido pela ANVISA. A seiva de C. lechleri parece ser pouco toxica, o que permite sua ampla aplicação para fins terapêuticos. Da mesma forma, ensaios de mutagenicidade também não demonstraram riscos. Entretanto, para o uso seguro, este composto ainda carece 
de uma série de ensaios que devem ser conduzidos em experimentos controlados. A toxicidade crônica tem de ser determinada, bem como níveis de irritabilidade cutânea e ocular. O uso seguro de fitoterápicos é uma tendência e agencias de proteção ao consumidor parecem estar exigindo cada vez mais que se trate fitoterápicos com a mesma exigência que outros fármacos, tanto no Brasil como em outros países.

Estudos relacionados à ação antidiarreica, bem como outros efeitos entéricos, também demonstraram avanço. Esta é a função mais bem descrita do sangue de dragão, bem como aquela para qual o mercado já esta estabelecido. Não havendo duvidas quanto ao seu valor terapêutico, esperase que o fitoterápico seja dado seu merecido destaque pela indústria farmacêutica brasileira. Outra área que parece ter tido algum avanço é a da ação antitumoral, ainda que a maioria dos estudos desenvolvidos nos últimos dez anos tenha sido in vitro, estes tem gerado resultados promissores e estudos em animais devem ser conduzidos.

Outras funções parecem evidentes e devem ser exploradas por pesquisadores. A necessidade da planta produzir um composto com ausência de taspina para atrair formigas parece indicar que esta tenha ação nociva ou repelente a insetos e esta função deve ser avaliada. Da mesma forma, outras linhas de pesquisa promissoras parecem ter ficado estagnadas nos últimos dez anos. Estudos com relação à utilização do sangue de dragão como auxiliar na cicatrização de feridas cutâneas devem ser retomados, bem como no tratamento de picaduras de insetos.

\section{Conclusão}

Parece evidente que o sangue de dragão, bem como a taspina, seu composto majoritário, tem funções diversas que devem ser exploradas por pesquisadores brasileiros. No entanto, existe um vazio de informações sobre os 
seus mecanismos de ação, a amplitude de suas aplicações e como eles podem ser combinados com outras abordagens terapêuticas. Nos últimos dez anos a pesquisa com esta seiva não foi tão produtiva em números como no passado, mas os estudos publicados são de alto valor cientifico e técnico. Esta pesquisa deve ser retomada tanto para nos tornarmos competitivos com os produtos que estão sendo comercializados a base de $C$. lechleri no exterior, quanto para fornecermos um produto de uso seguro e função validada ao nosso mercado consumidor.

\section{Agradecimentos}

Os autores agradecem a CAPES

e $\mathrm{CNPq}$ por conceder bolsas $(\mathrm{CNPq}-$ 305072/2012-9)

\section{Referências Bibliográficas}

AHMAD, R.; KHAN,

A. V.; SIDDIQUI, M.F.; HASNAIN, A.U. Effects of an aqueous extract of Croton bonplandianum Baill in rats.

\section{Environmental}

\section{Toxicology and Pharmacology,} v.26(3), p.336-41, 2008.

ALONSO-CASTRO, A. J.; SÁNCHEZ, E. O.; DOMÍNGUEZ, F.; TOLEDO, G. L.; CHÁvEZ, M.; TELLO, A. J. O.; CARRANCÁ, A. G.. Antitumor effect of Croton lechleri Mull. Arg. (Euphorbiaceae). Journal of Ethnopharmacology, v.140, p.438442, 2012.

AMARAL, A. C. F.; BARNES, R. A. Alkaloids of Croton celtidifolius. Planta Medica. Botanical Journal of the Linnean Society, v.141, p.399-436, 1997.

AZEVEDO, K.A.A.; LIMA, Á.; LEITE, A.; MELO, T.; COSTA, J.; PEREIRA， M.A.; CAMPOS， C.A.; LIMA, A. Guia para a extração de sangue de grado (Croton lechleri Müll. Arg.): recomendações técnicas para a extração de látex de sangue de grado (sangue de dragão). Rio BrancoAC: USAID/IPAM, 28p. 2008. 
AYALA，S,; ROJAS，J.; DÍAZ，D.;

JUÁREZ， J.; DELGADO,

C.

Evaluación de la toxicidad vaginal de

Croton lechleri en conejas. Anales de

la Faculade de Medicina, v.71(2), p.83-7, 2010.

BRASIL. Ministério da Saúde, Secretaria de Ciência, Tecnologia e Insumos Estratégicos, Departamento de Assistência Farmacêutica e Insumos Estratégicos.

Programa Nacional de Plantas Medicinais e Fitoterápicos, Brasília, v.135, 2009.

BRITO, N.D.S.; LIMA A.F.; COSTA, J.L.; TAVEIRA, U.S.; AZEVEDO K.S. Inventário e estudo da estrutura populacional de sangue de grado (Croton lechleri Muell. Arg.) para o manejo florestal comunitário no leste do estado do Acre, Brasil. Anais do VIII Congresso de Ecologia do Brasil, Caxambu - MG, 2007.
BEZERRA, D.P.; MARINHO FILHO, J.D.; ALVES,

A.P.; PESSOA, C.; MORAES, M.O.; PESSOA, O. D.; TORRES, M.C.; SILVEIRA， E. R.; VIANA， F.A.; LOTUFO， L.V.C. Antitumor activity of the essential oil from the leaves of Croton regelianus and its component ascaridole. Chemistry biodiversity, v.6(8), p.1224-1231, 2009.

CAI, Y.; EVANS, F. J.; ROBERTS, F. M.; PHILLIPSON, J.D; ZENK, H. M.GLEBAS Y.Y. Polyphenolic compounds from C.lechleri. Phytochemistry, v.30(6), p.2033-2040, 1991.

CAI, Y.; CHEN, Z. P.; PHILLIPSON, J.D. Diterpenes from C.lechleri. Phytochemistry, v.34 (1), p.755-760, $1993 a$.

CAI, Y.; CHEN, Z. P.; PHILLIPSON J.D. Clerodanes diterpenoids from $C$. lechleri. Phytochemistry, v.34(1), p.265-268, 1993 b. 
COSTA, R.M.A.; MENK, C.F.M. ECKSTEIN, P.; TACKSON, M.; Biomonitoramento de mutagênese MILLMAN, N.; SOBRERO, A. ambiental. Biotecnologia Ciência \& Comparison of vaginal tolerance test of

Desenvolvimento, p.24-26, 2000.

CUNHA, M. C. Relações e dissensões entre saberes tradicionais e saber científico. Revista da USP, São Paulo, v.75, p.76-84, 2007.

DI STASI, L.C.; HIRUMA-LIMA, C.A. Plantas Medicinais na Amazônia e na Mata Atlântica. Revista São Paulo: UNESP, 2d. 592p., 2002.

DINIZ, V. W. B.; DANTAS FILHO, H. A.; MÜLLER. $\quad$ R.C.S.K.G. FERNANDES. Classificação multivariada de ervas medicinais da região amazônica e suas infusões de Acordo com sua composição mineral. Quimica Nova, v.36, n.2, p. 257-261, 2013.

CRONQUIST, A. The evolution and classification of flowering plants. The New York Botanical Garden Press. 2ed, New York, USA. 555p., 1988. spermicidal preparation in rabbits and monkeys. Journal Of The Society For Reproduction And Fertility, v.20, p.85-93, 1996.

FÃO, F.; ZAN, R.A.; BRONDANI, F. M. M.; RAMOS, L.J.; MENEGUETTI, D.U.O. Análise do potencial mutagênico da seiva da casca de Croton lechleri (müll. arg), no estado de Rondônia, Amazônia Ocidental. SaBios: Revista de Saúde e Biologia, v.7, n.1, p. 91-98, 2012.

FAYAD, W.; FRYKNAS, M.; BRNJIC, S.; OLOFSSON, M. H.; LARSSON, R.; LINDER, S. Identification of a novel topoisomerase inhibitor effective in cells overexpres- sing drug efflux transporters. PLoS One, v.4(10), p.7238, 2009. 
FRANÇA-NETO, A.; TEIXEIRA, A. C.; MEDEIROS T. C.; FARIAS, M. D.

O. S. Q.; SAMPAIO, C. M.; SOUZA, A.N.C; LAHLOU, S.; CARDOSO, J.H. L. Essential oil of Croton argyrophylloides: toxicological aspects and vasorelaxant activity in rats.

Natural

Product

Communications, v.7(10), p.1397-400, 2012.

FRANCO, A.P.; PERES, A.R.; SOUZA， M.F.P.; QUEIROZ， M.S.; ASSIS, J.M.F. Ação de extratos vegetais sobre o desenvolvimento de fungos simbiontes das formigas cortadeiras. Engenharia Ambiental Espírito Santo do Pinhal, v.10, n.1, p.103-113, 2013.

FORERO, L.E.; CHÁVEZ, J.; BERNAL, H. Agrotecnología para el cultivo de sangre grado. Fundamentos de agrotecnología del cultivo de plantas medicinales iberoamericanas. Convênio Andrés Bello/Ciencia y Tecnología para el Desarrollo, Bogotá. p.157-190, 2000.

GOVAERTS， R.; FRODIN， D.G.; SMITH, A.R. World Chechklist and bibliography of Euphorbiaceae (with Pandaceae). The Royal Botanic Gardens, Kew, p.1-4, 2000.

GUIMARÃES, L.A.C.; SECCO, R.S. As espécies de Croton L. sect. Cyclostigma Griseb. e Croton L. sect. Luntia (Raf.) G.L. Webster subsect. Matourenses G.L. Webster (Euphorbiaceae s.s.) ocorrentes na Amazônia brasileira. Acta Amazonica, v.40(3), p.471-488, 2010.

FRANCO, A.P.; PERES, A.R.; SOUZA, M.F.P.; QUEIROZ, M.S.; ASSIS, J.M.F. Flavonoids from the Stems of Croton caudatus Geisel. var. tomentosus Hook. Molecules, v.15, p.1097-1102, 2010.

ITOKAWA, H.; ICHIHARA, Y.; MOCHIZUKA, M.; ENOMORI, T.; MORITA, H.; SHIROTA, O.; INAMATSU, M.; TAKEYA, K.A. 
cytotoxic substance from Sangue de Grado. Chemical and Pharmaceutical

Bulletin, v.39, p.1041-1042, 1991.

JONES, K. Review of sangre de drago (Croton lechleri) - a South American tree sap in the treatment of diarrhea, inflammation, insect bites, viral infections and wounds: traditional uses to clinical research. The Journal of Alternative and Complementary Medicine, v. 9, p.877-896, 2003.

KING, S.R.; MEZA, E.; AYALA, F.; FORERO, L.E.; PENA, M.; ZAK, V.; BASTIEN, H. Croton lechleri and the sustainable harvest and management of plants in pharmaceuticals, phytomedicines and cosmetics industries. International Symposium on Herbal Medicine. International Institute for Human Resources Development/College of Health and Human Services/ San Diego State University, San Diego, CA. p. 305-333, 1997.
LEAL, I. R. Dispersão de sementes por formigas na caatinga. Ecologia e conservação da caatinga. Recife: Editora Universitária da UFPE, p. 593624, 2003.

LOPES, D.; BIZZO, H.R.; SÁSOBRINHO, A.F.; PEREIRA, M.V.G. Essential oil from leaves of Croton sacaquinha Benth. The Journal of Essential, Oil Research, v.15(1), p.4849, 2003.

MACIEL, M.A.M. et al. Plantas medicinais: a necessidade de estudos multidisciplinares. Química Nova, v.25, p.429-438, 2002.

MAIA, J.M.A.; CZECZKO, N.G.; RIBAS FILHO, J.M.; DIETZ, U.A.; DUCK, D.; RIBAS, C.A.P. M.; SANTOS, E.A.; BAPTISTELLA, E.; WALLBACH, T.Z.; VALE， J.R.; YAGUSHITA, N. Estudo da cicatrização de suturas na bexiga urinária de ratos com e sem a utilização de extrato bruto de Jatropha gossypiifolia L. intraperitoneal. Acta 
Cirúrgica Brasileira, v.21 CHARBONNET, R.M.; BOBROWSKI, (Suplemento 2), 2006.

P.; LAO, J.; TRENTACOSTI, A.M.;

MURILLO， R.M.; JAKUPOVIC， J.; SANDOVAL, M. Treatment of gastric

RIVERA， J.; CASTRO, V.H. ulcers and diarrhoea with the

Diterpenes and other constituents from

Croton draco (Euphorbiaceae). Revista de Biologia Tropical, 49(1): p. 259264, 2001.

MARINO, S.; GALA, F.; ZOLLO, F.; VITALINI, S.; FICO. G.; VISIOLI, F.; IORIZZI, M. Identification of Minor Secondary Metabolites from the Latex of Croton lechleri (Muell-Arg) and Evaluation of Their Antioxidant Activity. Molecules, 13, p. 1219-1229, 2008.

MILANOWSKI, D.J.; WINTER, R.E. K.; ELVIN-LEWIS, M.P.F.; LEWIS, W.H. Geographic distribution of three alkaloid chemotypes of Croton lechleri.

The Journal of Natural Products, v.65, p.814-819, 2002.

MILLER,

M.J.S.;

MACNAUGHTON,W. K.; ZHANG, X. THOMPSON, J.H.;

Amazonian herbal medicine sangre de grado. American Journal of Physiology. Gastrointestinal and Liver Physiology, v.279, p.192-200, 2000.

MONTOPOLI, M.; BERTIN, R.; CHEN, Z.; BOLCATO, J.; CAPARROTTA, L.; FROLDI, G. Croton lechleri sap and isolated alkaloid taspine exhibit inhibition against human melanoma SK23 and colon cancer HT29 cell lines. Journal of Ethnopharmacology, v.144, p.747753, 2012.

NEIVA， T.J.C.; MORAES， A.C.R.; BUCHELE，C.; PIZZOLATTI，M.G.; D'AMICO, E.A.; FRIES, D.M. ROCHA, T.R.F. Antiplatelet activity of Croton celditifolius. Revista Brasileira de Ciências 
Farmacológica, v.44, n.1, p.133- Biociências, v. 5, supl.2, p.177-179, $141,2008$. 2007.

OLIVEIRA, A.C.; CARDOSO, J.H.L.;

PIETERS, L. Isolation of SANTOS, C.F.; MORAIS, S.M.; dihygrobenzofuran lignan from South SOUZA, A.N.C. Antinociceptive American dragon's blood (Croton sp) as effects of the essential oil of Croton zehntneri im mice. Brazilian Journal of Medical and Biological Research, v. 34, p.1471-1474, 2001.

OLIVEIRA, F.C.S.; BARROS, R.F. M.; MOITA NETO, J.M. Plantas medicinais utilizadas em comunidades rurais de Oeiras, semiárido piauiense. Revista Brasileira de Plantas Medicinais, Botucatu, v.12, n.3, p.282-301, 2010.

PALAZZINO， G.; FEDERICI， E.; RASOANAIVO, P.; GALEFFI.C; MONACHE, F.D. 3,4 - seco diterpenes of Croton geayi. Gazzeta Chimica Italiana, v.127, p.311-314, 1997. PERCY, A.; ZEVALLOS, P.; FILHO, M. T. Espécies lenhosas do gênero Croton L. (Euphorbiaceae) No Estado do Acre. Revista Brasileira de an inhibitor of cell proliferation. Journal Natural Products, v.56, n.6, p.889-906, 1993.

REIS, P.S.; ESTEVAM, I.H.S.; SANTOS, W.P.C.; KORN, M.G.A.; DAVID, J.M.; DAVID, J.P.; ARAÚJO, R.G.O.; PIMENTEL, $\quad$ M.F.; FERREIRA， S. L. C. Mineral composition of Lippia alba (Mill.) N.E. Brown leaves. Journal of the Brazilian Chemical Society, v.21, n.10, p.19051909, 2010.

ROLLINGER，J.M.; SCHUSTER，D.; BAIER, E.; ELLMERER, E.P.; LANGER, T.; STUPPNER, H. Taspine: bioactivity-guided isolation and molecular ligand-target insight of a potent acetyl-cholinesterase inibitor from Magnolia x soulangiana. Journal 
of Natural Products, v.69, p.13411346, 2006.

ROSSI, $\quad$ D.; $\quad$ GUERRINI,A.; PAGANETTO, G.; BERNACCHIA, G.; CONFORTI， F.; STATTI， G.; MAIETTI, S.; POPPI, I.; TACCHINI, M.; SACCHETTI, G. Croton lechleri Mull. Arg. Euphorbiaceae) stem bark essential oil as possible mutagenprotective food ingredient against heterocyclic amines from cooked food.

Food Chemistry, v.139, p.439-447, 2013.

ROSSI, D.; BRUNI, R.; BIANCHI, N.; CHIARABELLI，C.; GAMBARI，R.; MEDICI, A.; LISTA, A.; PAGANETTO, G. Evaluation of the mutagenic, antimutagenic and antiproliferative potential of Croton lechleri Muell. Arg. latex. Phytomedicine, v.10, p.139-144, 2003. ROSSI, D.; GUERRINI, A.; MAIETTI, S., BRUNI, R.; PAGANETTO, G.; POLI, F.; SCALVENZI, L.; RADICE, M.; SARO, K.; SACCHETTI, G.
Chemical fingerprinting and bioactivity of Amazonian Ecuador Croton lechleri Müll. Arg. (Euphorbiaceae) stem bark essential oil: A new functional food ingredient? Food Chemistry, v.126, P. 837-848, 2011.

SANDOVAL, M.; AYALA, S.; ORÉ, R.; LOLI, A.; HUAMÁN, O.; VALDIVIESO, R.; BÉJAR, E. Capacidad antioxidante de la sangre de grado (Croton palanostigma) sobre la mucosa gástrica, en animales de experimentación. Anales de la Facultad de Medicina, v.67(3), p.199$205,2006$.

SANVODAL, M.; AYALA, S.; ORÉ, R.; LOLI, R.; HUAMÁN, O. Estimulación de la actividad péptica del jugo gástrico, inducida por látex de Croton palanostigma (sangre de grado). Anales de la Facultad de Medicina, v.69(3), p.164-167, 2008.

SALATINO, A.; FARIA SALATINO, M. L.; NEGRI, G. Traditional uses, chemistry and pharmacology of Croton 
species (Euphorbiaceae). Journal of the Brazilian Chemical Society, v.18(1), p.11-33, 2007.

SECCO, R. S. A new species de Croton sect. Geiseleria (Euphorbiaceae) from Eastern Amazonian, Brazil. Revista Brasileira de Botânica, v.32(2), p.249252, 2009.

SILVA, L.K.; FILHO, C. V. Plantas do gênero Bauhinia: Composição Química e potencial farmacológico. Química Nova, v.25(3), p.449-454, 2002.

SECCO, R. S.; BERRY, P. E.; ROSA, N. A. Croton diasii and Croton trombetensis two new Euphorbiaceae from Amazonian, Brazil. Novon, v.11(1), p.119-123, 2001.

SILVA， R.M.; OLIVEIRA， F.A.; CUNHA, K.M.; MAIA, J.L.; MACIEL, M.A.; PINTO, A.C. Cardiovascular effects of trans-dehydrocrotonin, a diterpene from Croton cajucara in rats.

Vascular Pharmacology, v.43(1), p.11-18, 2005.
SMITH, B.A. A new species of Croton (Euphorbiaceae) from Ecuador. department of environmental studies, Emory University, 400 dowman drive, Atlanta Georgia. Novon. A Journal For Botanical Nomenclature From The Missouri Botanical Garden, v.16, n.1, p.273-274, 2006.

UBILLAS， R..; JOLAD， S.D.; BRUENING，R.C.; KERNAN，M.R.; KING, S.R. ; KING SESIN, D.F.; BARRETT, M.; STODDART, C.A.; FLASTER, T.; KUO, J.; AYALS, F.; MEZA， E.; CASTANEL， M.; MCMEEKIN， D.; ROZHON， E.; TEMPESTA, M. S.; BARNARD, D.; HUFFMAN, J.; SMEE, D.; SIDWELL, R.; SOIKE， K.; BRAZIER， A.; SAFRIN, S.; ORLANDO, R.; KENNY, P.T.M.; BEROVA, N.; NAKANISHI, K. SP-303, An antiviral oligomeric proanthocyanidin from the latex of Croton lechleri (Sangre de Drago). Phytomedicine, v.1, p.77-106, 1994. 
VALlE, J.S.; FONSECA, B.K.D.; Missouri Botanical Garden, v.81(1), NAKAMURA, S.S.; LINDE, G.A.; p.3-32, 1993.

MATTANA, R.S.; MING, L.C.; ZEVALLOS-POLLITO, P.A.Z.;

COLAUTO, N.B. Diversidade genética de populações naturais de pariparoba [Pothomorphe umbellata (L.) Miq.] por RAPD. Revista Brasileira de Plantas Medicinais, v.15, n.1, p.47-53, 2013. VIEIRA, A. et al. Efeito genotóxico da infusão de capítulos florais de camomila. Revista Trópica. Ciências Agrárias e Biológicas, v.3, n.1, 2009. WEBSTER, G.L. A provisional synopsis of the section of the genus Croton (Euphorbiaceae). Annals of
TOMAZELLO, M.F. Espécies lenhosas do gênero Croton L. (Euphorbiaceae) no Estado do Acre. Revista Brasileira de Biociências, v.5(2), p.177-179, 2007.

ZHANG, Y.; HE, L.; ZHOU, Y. Taspine isolated from Radix et Rhizoma Leonticis inhibits growth of human umbilical vein endothelial cell (HUVEC) by inducing its apoptosis. Phytomedicine, v.15, p.112-119, 2008. 